\title{
OPEN Trends in mortality rate in patients with congenital heart disease undergoing noncardiac surgical procedures at children's hospitals
}

\author{
Viviane G. Nasr ${ }^{1 \bowtie}$, Steven J. Staffa ${ }^{1}$, David Faraoni \& James A. DiNardo $^{1}$
}

Advances made in pediatric cardiology, cardiac surgery and critical care have significantly improved the survival rate of patients with congenital heart disease (CHD) leading to an increase in children with CHD presenting for noncardiac surgical procedures. This study aims (1) to describe the trend and perioperative mortality rates in patients with $\mathrm{CHD}$ undergoing noncardiac surgical procedures at children's hospitals over the past 5 years and (2) to describe the patient characteristics and the most common type of surgical procedures. The Pediatric Health Information System (PHIS) is an administrative database that contains inpatient, observation, and outpatient surgical data from 52 freestanding children's hospitals. Thirty-nine of the $\mathbf{5 2}$ hospitals submitted data on all types of patient encounters for the duration of the study from 2015 to 2019. The total numbers of non-cardiac surgical encounters among patients with history of a CHD diagnosis significantly increased each year from 38,272 in 2015 to 45,993 in $2019(P<0.001)$. Despite the increase in case numbers, there has been a significant decline in mortality rates to the most recent incidence of $1.06 \%$ in 2019 . Careful patient selection and medical optimization of patients aligned with specific expertise at dedicated children's hospitals may lead to improvement in mortality rate. Future studies comparing the outcomes of patients with cardiac disease based on hospital type and volume as well as type of providers may help determine the future of care including potential need for regionalization of noncardiac care for this vulnerable patient population.

The prevalence of moderate to severe congenital heart disease (CHD) in the United States is estimated to be 6 per 1000 live-born full term infants ${ }^{1}$. Advances made in pediatric cardiology, cardiac surgery and critical care have significantly improved the survival rate of patients with CHD leading to increases in the populations of children and adults with significant $\mathrm{CHD}^{2,3}$. Children with $\mathrm{CHD}$ frequently undergo diagnostic and interventional procedures that require sedation or general anesthesia. Analysis of the Pediatric Health Information System (PHIS) database between 2004 and 2012 demonstrated that $41 \%$ of children who had undergone surgery to correct CHD in the first year of life also underwent at least one non-cardiac surgical procedure by age $5^{4}$. Patients with CHD are generally considered at higher risk for cardiac arrest, perioperative mortality and major morbidity than those without $\mathrm{CHD}^{5-8}$.

In a comprehensive analysis of data from the University Hospital Consortium, 191,261 inpatient, non-cardiac procedures occurring between 1993 and 1996 in pediatric patients were analyzed. Mortality was 3.8\% in the patients without CHD and $6.0 \%$ in the patients with CHD [odds ratio (OR) 3.53, confidence interval (CI) $3.15-3.95]^{5}$. From 1994 to 2005, the POCA Registry collected data on 373 anesthesia-related cardiac arrests (CA) in children ${ }^{6}$. Thirty-four percent of patients $(n=127)$ had heart disease (HD) (congenital or acquired). Mortality was $33 \%$ in patients with $\mathrm{HD}$ as compared to $23 \%$ in those without $\mathrm{HD}^{6}$. In a recent study, using the American College of Surgeons National Surgical Quality Improvement Program (ACS NSQIP) database, and after exclusion of the patient without $\mathrm{CHD}$ and those with minor $\mathrm{CHD}$, the incidence of mortality was $4.7 \%$ in a derivation cohort and $4.0 \%$ in the validation cohort ${ }^{9}$. These investigations were conducted over a period of two decades and utilized different datasets. In addition, none of those studies have looked at changes in number of cardiac patients with CHD requiring noncardiac procedures over time, neither at the change in mortality rate. Therefore, drawing any inferences about trends in mortality of patients with CHD over time is not possible.

${ }^{1}$ Department of Anesthesiology, Critical Care and Pain Medicine, Boston Children's Hospital, Harvard Medical School, 300 Longwood Avenue, Boston, MA 02115, USA. ²Department of Anesthesia and Pain Medicine, The Hospital for Sick Children, University of Toronto, Toronto, Canada. ${ }^{\circledR}$ email: viviane.nasr@childrens.harvard.edu 


\begin{tabular}{|c|c|c|c|c|c|}
\hline Variable & 2015 & 2016 & 2017 & 2018 & 2019 \\
\hline Number of cases & 38,272 & 40,313 & 41,454 & 43,854 & 45,993 \\
\hline Age (years) & $2.8(0.9,6.5)$ & $2.9(0.9,6.7)$ & $3(1,7)$ & $3.2(1,7.2)$ & $3.4(1.1,7.6)$ \\
\hline Neonates $(<30$ days $)$ & $3246(8.5 \%)$ & $3393(8.4 \%)$ & $3459(8.3 \%)$ & $3492(8 \%)$ & $3520(7.7 \%)$ \\
\hline Infants ( 30 days to $<1$ year) & $6958(18.2 \%)$ & $7073(17.6 \%)$ & $7082(17.1 \%)$ & $7377(16.8 \%)$ & $7287(15.8 \%)$ \\
\hline 1 to $<5$ years & $15,437(40.3 \%)$ & $16,092(39.9 \%)$ & $16,329(39.4 \%)$ & $17,094(39 \%)$ & $17,608(38.3 \%)$ \\
\hline 5 to $<12$ years & $8576(22.4 \%)$ & $9399(23.3 \%)$ & $10,031(24.2 \%)$ & $10,837(24.7 \%)$ & $12,092(26.3 \%)$ \\
\hline 12 years or older & $4055(10.6 \%)$ & $4356(10.8 \%)$ & $4553(11 \%)$ & $5054(11.5 \%)$ & $5486(11.9 \%)$ \\
\hline \multicolumn{6}{|l|}{ Gender } \\
\hline Female & $16,179(42.3 \%)$ & $17,287(42.9 \%)$ & $17,481(42.2 \%)$ & $18,626(42.5 \%)$ & $19,726(42.9 \%)$ \\
\hline Male & $22,089(57.7 \%)$ & $23,017(57.1 \%)$ & $23,965(57.8 \%)$ & $25,225(57.5 \%)$ & $26,263(57.1 \%)$ \\
\hline Unknown & $4(0.01 \%)$ & $9(0.02 \%)$ & $8(0.02 \%)$ & $3(0.01 \%)$ & $4(0.01 \%)$ \\
\hline Birth weight (kg) & $2594(1390,3210)$ & $2637(1580,3210)$ & $2620(1510,3201)$ & $2630(1500,3203)$ & $2630(1535,3218)$ \\
\hline \multicolumn{6}{|l|}{ Race } \\
\hline White & $26,260(68.6 \%)$ & $27,775(68.9 \%)$ & $28,542(68.9 \%)$ & $30,134(68.7 \%)$ & $31,178(67.8 \%)$ \\
\hline Black & $6087(15.9 \%)$ & $6509(16.2 \%)$ & $6816(16.4 \%)$ & $7248(16.5 \%)$ & $7997(17.4 \%)$ \\
\hline Asian & $1012(2.6 \%)$ & $1116(2.8 \%)$ & $1254(3 \%)$ & $1342(3.1 \%)$ & $1411(3.1 \%)$ \\
\hline Pacific Islander & $123(0.3 \%)$ & $129(0.3 \%)$ & $154(0.4 \%)$ & $165(0.4 \%)$ & $188(0.4 \%)$ \\
\hline American Indian & $219(0.6 \%)$ & $207(0.5 \%)$ & $216(0.5 \%)$ & $244(0.6 \%)$ & $256(0.6 \%)$ \\
\hline Other & $3992(10.4 \%)$ & $3783(9.4 \%)$ & $3584(8.7 \%)$ & $3725(8.5 \%)$ & $4088(8.9 \%)$ \\
\hline \multicolumn{6}{|l|}{ Ethnicity } \\
\hline Hispanic or Latino & $6152(16.1 \%)$ & $6244(15.5 \%)$ & $6423(15.5 \%)$ & $7110(16.2 \%)$ & $7279(15.8 \%)$ \\
\hline Not Hispanic or Latino & $29,918(78.2 \%)$ & $31,636(78.5 \%)$ & $32,418(78.2 \%)$ & $34,366(78.4 \%)$ & $36,200(78.7 \%)$ \\
\hline Unknown & $2202(5.8 \%)$ & $2433(6 \%)$ & $2613(6.3 \%)$ & $2378(5.4 \%)$ & $2514(5.5 \%)$ \\
\hline \multicolumn{6}{|l|}{ Insurance } \\
\hline Private & $15,693(41 \%)$ & $16,713(41.5 \%)$ & $17,148(41.4 \%)$ & $18,089(41.3 \%)$ & $18,854(41 \%)$ \\
\hline Government & $21,540(56.3 \%)$ & $22,588(56 \%)$ & $23,205(56 \%)$ & $24,134(55 \%)$ & $16,636(54 \%)$ \\
\hline Other $^{\mathrm{a}}$ & $1039(2.7 \%)$ & $1012(2.5 \%)$ & $1101(2.7 \%)$ & $1631(3.7 \%)$ & $10,493(5 \%)$ \\
\hline Zip code income & & $\mathrm{n}=39,111$ & $\mathrm{n}=40,437$ & $\mathrm{n}=42,801$ & $\mathrm{n}=44,733$ \\
\hline $1-39,999$ & $16,786(45.3 \%)$ & $17,826(45.6 \%)$ & $18,596(46 \%)$ & $19,694(46 \%)$ & $20,317(45.4 \%)$ \\
\hline $40,000-49,999$ & $8792(23.7 \%)$ & $9203(23.5 \%)$ & $9333(23.1 \%)$ & $10,076(23.5 \%)$ & $10,505(23.5 \%)$ \\
\hline 50,000-65,999 & $7733(20.9 \%)$ & $8159(20.9 \%)$ & $8371(20.7 \%)$ & $8755(20.5 \%)$ & $9126(20.4 \%)$ \\
\hline $66,000+$ & $3717(10 \%)$ & $3923(10 \%)$ & $4137(10.2 \%)$ & $4276(10 \%)$ & $4785(10.7 \%)$ \\
\hline \multicolumn{6}{|l|}{ Comorbidities } \\
\hline Vent dependent & $5494(14.4 \%)$ & $5837(14.5 \%)$ & $6001(14.5 \%)$ & $6198(14.1 \%)$ & $6175(13.4 \%)$ \\
\hline Any complex chronic condition & $28,389(74.2 \%)$ & $28,963(71.9 \%)$ & $3009(72.4 \%)$ & $32,396(73.9 \%)$ & $34,232(74.4 \%)$ \\
\hline Gastrointestinal & $11,274(29.5 \%)$ & $12,099(30 \%)$ & $12,683(30.6 \%)$ & $13,600(31 \%)$ & $14,525(31.6 \%)$ \\
\hline Hematologic or immunologic & $1896(5 \%)$ & $1910(4.7 \%)$ & $1958(4.7 \%)$ & $2133(4.9 \%)$ & $2207(4.8 \%)$ \\
\hline Malignancy & $1552(4.1 \%)$ & $1573(3.9 \%)$ & $1615(3.9 \%)$ & $1731(4 \%)$ & $1884(4.1 \%)$ \\
\hline Metabolic & $1887(4.9 \%)$ & $1891(4.7 \%)$ & $1982(4.8 \%)$ & $2118(4.8 \%)$ & $2182(4.7 \%)$ \\
\hline Neurologic and neuromuscular & $5807(15.2 \%)$ & $5867(14.6 \%)$ & $6170(14.9 \%)$ & $6798(15.5 \%)$ & $7023(15.3 \%)$ \\
\hline Renal and urologic & $3743(9.8 \%)$ & $3852(9.6 \%)$ & $3980(9.6 \%)$ & $4528(10.3 \%)$ & $4740(10.3 \%)$ \\
\hline Respiratory & $6522(17 \%)$ & $6749(16.7 \%)$ & $7088(17.1 \%)$ & $7765(10.3 \%)$ & $8030(17.5 \%)$ \\
\hline Premature and neonatal & $3237(8.5 \%)$ & $3624(9 \%)$ & $4042(9.8 \%)$ & $4406(10.1 \%)$ & $4538(9.9 \%)$ \\
\hline Technology dependent & $13,670(35.7 \%)$ & $14,187(35.2 \%)$ & $14,749(35.6 \%)$ & $16,005(36.5 \%)$ & $16,780(36.5 \%)$ \\
\hline \multicolumn{6}{|l|}{ Syndromes } \\
\hline 22q11 deletion syndrome & $771(2 \%)$ & $763(1.9 \%)$ & $789(1.9 \%)$ & $842(1.9 \%)$ & $937(2 \%)$ \\
\hline Down syndrome & $3889(10.2 \%)$ & $4262(10.6 \%)$ & $4503(10.9 \%)$ & $4596(10.5 \%)$ & $4868(10.6 \%)$ \\
\hline
\end{tabular}




\begin{tabular}{|l|l|l|l|l|l|}
\hline Variable & 2015 & 2016 & 2017 & 2018 & 2019 \\
\hline Trisomy 13, 18 & $204(0.5 \%)$ & $213(0.5 \%)$ & $243(0.6 \%)$ & $258(0.6 \%)$ & $291(0.6 \%)$ \\
\hline Prematurity (weeks) & $480(1.3 \%)$ & $504(1.3 \%)$ & $467(1.1 \%)$ & $489(1.1 \%)$ & $499(1.1 \%)$ \\
\hline$<24$ & $7877(20.6 \%)$ & $7987(19.8 \%)$ & $8547(20.6 \%)$ & $9328(21.3 \%)$ & $9888(21.5 \%)$ \\
\hline $24-36$ & $4140(10.8 \%)$ & $4668(11.6 \%)$ & $4913(11.9 \%)$ & $5174(11.8 \%)$ & $5861(12.7 \%)$ \\
\hline $37-38$ & $25,775(67.4 \%)$ & $27,154(67.4 \%)$ & $27,527(66.4 \%)$ & $28,863(65.8 \%)$ & $29,745(64.7 \%)$ \\
\hline Term (39 weeks or more) & $33,158(86.6 \%)$ & $5333(13.2 \%)$ & $5452(13.2 \%)$ & $5818(13.3 \%)$ & $5859(12.7 \%)$ \\
\hline Intensive care unit flag & $3416(8.9 \%)$ & $3665(9.1 \%)$ & $3789(9.1 \%)$ & $3755(8.6 \%)$ & $3821(8.3 \%)$ \\
\hline Neonatal intensive care unit flag & & & &
\end{tabular}

Table 1. Demographics and patient characteristics of patients with congenital heart disease undergoing noncardiac surgery. Insurance: government includes: in-state and out-of-state medicaid, medicare, TRICARE, CHIP and other government. Intensive care unit (ICU) flag and neonatal intensive care unit (NICU) flag: patient had an ICU or NICU stay during their hospital encounter. ${ }^{a}$ Other payor, self-pay, charity, and unknown.

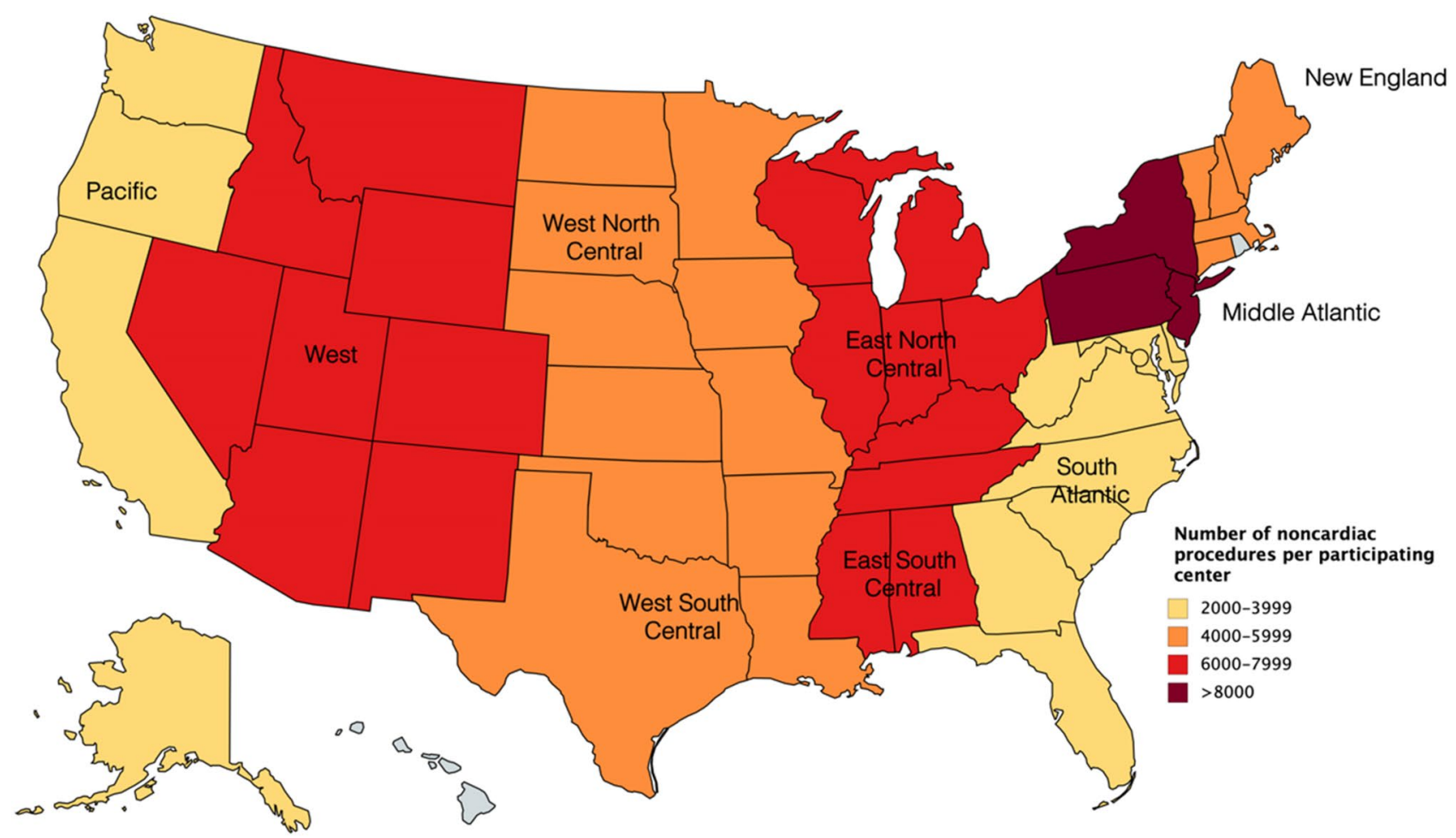

Figure 1. Number of noncardiac procedures per participating center in the United States. The map was created using mapchart.net (https://mapchart.net/usa.html).

This study aims (1) to describe the trend and perioperative mortality rates in patients with CHD undergoing noncardiac surgical procedures at children's hospitals over the past 5 years and (2) to describe the patient characteristics and the most common type of surgical procedures performed during that same time interval.

\section{Methods}

Data source. The Pediatric Health Information System (PHIS) is an administrative database that contains inpatient (more or equal to $24 \mathrm{~h}$ stay), observation ( $<24 \mathrm{~h}$ admission), and ambulatory (outpatient) surgery discharge/encounter data from 52 freestanding children's hospitals that are part of the Children's Hospital Association. The PHIS contains International Classification of Diseases 9th and 10th Revision, Clinical Modification (ICD-9-CM) and (ICD-10-CM) diagnostic and procedure codes, date-stamped billing data, and other administrative data ${ }^{10}$. Only hospitals that submitted data from all encounter types during the entire time period of study were included. 


\begin{tabular}{|c|c|c|c|c|c|c|}
\hline Variable & 2015 & 2016 & 2017 & 2018 & 2019 & $\begin{array}{l}\text { P value for } \\
\text { trend }\end{array}$ \\
\hline $\begin{array}{l}\text { Number of total } \\
\text { encounters }\end{array}$ & 38,272 & 40,313 & 41,454 & 43,854 & 45,993 & $<0.001^{*}$ \\
\hline $\begin{array}{l}\text { Number of unique } \\
\text { patients }\end{array}$ & 28,239 & 30,102 & 31,282 & 32,889 & 34,744 & \\
\hline $\begin{array}{l}\text { Range of number } \\
\text { of encounters per } \\
\text { patient }\end{array}$ & 1 to 23 & 1 to 28 & 1 to 18 & 1 to 27 & 1 to 31 & \\
\hline Mortality rate & \begin{tabular}{|l|}
$445 / 38,272$ \\
$(1.16 \%)$
\end{tabular} & \begin{tabular}{|l|}
$524 / 40,313$ \\
$(1.30 \%)$
\end{tabular} & $\begin{array}{l}509 / 41,454 \\
(1.23 \%)\end{array}$ & \begin{tabular}{|l|}
$477 / 43,854$ \\
$(1.09 \%)$
\end{tabular} & \begin{tabular}{|l|}
$489 / 45,993$ \\
$(1.06 \%)$
\end{tabular} & $0.01^{*}$ \\
\hline \multicolumn{7}{|l|}{ Type of patient } \\
\hline Inpatient & 14,469 & 14,961 & 15,044 & 15,742 & 15,839 & $0.006^{*}$ \\
\hline Mortality rate & $445(3.08 \%)$ & $523(3.50 \%)$ & $509(3.38 \%)$ & $475(3.02 \%)$ & $486(3.07 \%)$ & \\
\hline $\begin{array}{l}\text { Outpatient (ambu- } \\
\text { latory) }\end{array}$ & 19,719 & 21,189 & 22,312 & 23,911 & 25,890 & $<0.001^{*}$ \\
\hline Mortality rate & $0(0 \%)$ & $0(0 \%)$ & $0(0 \%)$ & $0(0 \%)$ & $2(0.01 \%)$ & \\
\hline Observation unit & 4084 & 4163 & 4098 & 4201 & 4264 & 0.071 \\
\hline Mortality rate & $0(0 \%)$ & $1(0.02 \%)$ & $0(0 \%)$ & $2(0.05 \%)$ & $1(0.02 \%)$ & \\
\hline \multicolumn{7}{|l|}{ Length of stay } \\
\hline Inpatients & $7(2,27)$ & $7(3,30)$ & $7(3,31)$ & $8(3,30)$ & $8(3,30)$ & \\
\hline
\end{tabular}

Table 2. Description of number of encounters, patients, mortality rate and length of stay. Observation means stay strictly less than $24 \mathrm{~h}$.

\begin{tabular}{|c|c|c|c|c|c|c|c|c|c|}
\hline \multicolumn{2}{|l|}{2015} & \multicolumn{2}{|l|}{2016} & \multicolumn{2}{|l|}{2017} & \multicolumn{2}{|l|}{2018} & \multicolumn{2}{|l|}{2019} \\
\hline Diagnosis & $(\%)$ & Diagnosis & $(\%)$ & Diagnosis & $(\%)$ & Diagnosis & $(\%)$ & Diagnosis & $(\%)$ \\
\hline Atrial septal defect & 38.99 & Atrial septal defect & 32.28 & Atrial septal defect & 32.00 & Atrial septal defect & 31.77 & Atrial septal defect & 32.47 \\
\hline Patent ductus arteriosus & 15.03 & Patent ductus arteriosus & 14.86 & Patent ductus arteriosus & 14.75 & Patent ductus arteriosus & 13.90 & Patent ductus arteriosus & 13.99 \\
\hline Ventricular septal defect & 5.55 & Ventricular septal defect & 12.54 & Ventricular septal defect & 11.94 & Ventricular septal defect & 11.78 & Ventricular septal defect & 11.49 \\
\hline $\begin{array}{l}\text { Congenital insufficiency } \\
\text { of aortic valve }\end{array}$ & 4.95 & $\begin{array}{l}\text { Congenital insufficiency } \\
\text { of aortic valve }\end{array}$ & 4.65 & $\begin{array}{l}\text { Congenital insufficiency } \\
\text { of aortic valve }\end{array}$ & 4.75 & $\begin{array}{l}\text { Congenital insufficiency } \\
\text { of aortic valve }\end{array}$ & 5.02 & $\begin{array}{l}\text { Congenital insufficiency } \\
\text { of aortic valve }\end{array}$ & 4.80 \\
\hline $\begin{array}{l}\text { Stenosis of pulmonary } \\
\text { artery }\end{array}$ & 3.53 & $\begin{array}{l}\text { Stenosis of pulmonary } \\
\text { artery }\end{array}$ & 3.55 & $\begin{array}{l}\text { Stenosis of pulmonary } \\
\text { artery }\end{array}$ & 3.36 & $\begin{array}{l}\text { Stenosis of pulmonary } \\
\text { artery }\end{array}$ & 3.34 & $\begin{array}{l}\text { Stenosis of pulmonary } \\
\text { artery }\end{array}$ & 3.47 \\
\hline $\begin{array}{l}\text { Hypoplastic left heart } \\
\text { syndrome }\end{array}$ & 3.24 & Tetralogy of fallot & 2.33 & $\begin{array}{l}\text { Hypoplastic left heart } \\
\text { syndrome }\end{array}$ & 2.25 & $\begin{array}{l}\text { Hypoplastic left heart } \\
\text { syndrome }\end{array}$ & 2.52 & $\begin{array}{l}\text { Hypoplastic left heart } \\
\text { syndrome }\end{array}$ & 2.52 \\
\hline
\end{tabular}

Table 3. Most common cardiac diagnoses codes in patients with congenital heart disease presenting for a surgical procedure.

Patient population. Patients less than 18 years of age and undergoing a noncardiac procedure between January 2015 and December 2019 who had an ICD-9-CM diagnosis code for CHD (745.0-747.49) or ICD10-CM diagnosis code (Q 20.0-Q 26.9) at anytime during the past 10 years 2000 to 2019. Patients who did not have an ICD-9-CM or ICD-10-CM diagnosis of CHD were excluded ${ }^{11}$. Cardiac surgeries and catheter-based interventions were excluded. The frequencies of all noncardiac surgical procedures performed were examined. A non-cardiac surgical procedure was defined as a procedure performed in an operating room (operating room flag in the PHIS database) and with a documented surgical procedure code. The intrinsic surgical risk is the risk of 30-day mortality associated with specific surgical procedures as defined by current procedural terminology $(\mathrm{CPT})^{12}$. Surgical procedures with CPT risk quartiles 1 and 2 comprise the low-risk procedure category, and quartiles 3 and 4 comprise the high-risk procedures.

Statistical methods. Demographics and patient characteristics are described for encounters of CHD patients undergoing non-cardiac surgery using frequencies and percentages for categorical data, and medians with interquartile ranges (IQR) for continuous data, stratified by year. Mortality rates over time in the entire group and stratified by patient type are expressed as percentages and trends were evaluated using the CochranArmitage test across the study years. Trends of the number of cases across the study years were evaluated using generalized linear modeling. The most common cardiac diagnoses based on ICD diagnosis coding is presented by year, as well as the most common non-cardiac procedures with intrinsic surgical risk quartile (ISR). The number of cases based on region of the US is graphically depicted using a heat-map. A two-tailed P value threshold of $\mathrm{P}<0.05$ was implemented for determining statistical significance. Stata (version 16.0, StataCorp LLC., College Station, TX, USA) was used for all statistical analyses. 


\begin{tabular}{|c|c|}
\hline Outpatient procedures & Intrinsic surgical risk \\
\hline \multicolumn{2}{|l|}{2015} \\
\hline Incision in the middle ear & 1 \\
\hline Myringotomy & 1 \\
\hline Dentoalveolar procedure & N/A \\
\hline Endoscopy procedures on the larynx & 1 \\
\hline Esophagogastroduodenoscopy & 1 \\
\hline \multicolumn{2}{|l|}{2016} \\
\hline Incision in the middle ear & 1 \\
\hline Dentoalveolar procedure & $\mathrm{N} / \mathrm{A}$ \\
\hline Drainage of left middle ear (open approach) & 1 \\
\hline Esophagogastroduodenoscopy & 1 \\
\hline Endoscopy procedures on the larynx & 1 \\
\hline \multicolumn{2}{|l|}{2017} \\
\hline Incision in the middle ear & 1 \\
\hline Dentoalveolar procedure & $\mathrm{N} / \mathrm{A}$ \\
\hline Drainage of left middle ear (open approach) & 1 \\
\hline Esophagogastroduodenoscopy & 1 \\
\hline Endoscopy procedures on the larynx & 1 \\
\hline \multicolumn{2}{|l|}{2018} \\
\hline Incision in the middle ear & 1 \\
\hline Dentoalveolar procedure & N/A \\
\hline Esophagogastroduodenoscopy & 1 \\
\hline Endoscopy procedures on the larynx & 1 \\
\hline Drainage of left middle ear (open approach) & 1 \\
\hline \multicolumn{2}{|l|}{2019} \\
\hline Incision in the middle ear & 1 \\
\hline Dentoalveolar procedure & N/A \\
\hline Esophagogastroduodenoscopy & 1 \\
\hline Endoscopy procedures on the larynx & 1 \\
\hline Excision and destruction procedures on the pharynx, adenoids, and tonsils & 1 \\
\hline
\end{tabular}

Table 4. Most common outpatient noncardiac procedures.

\section{Results}

Thirty-nine of the 52 participating hospitals in PHIS submitted data on inpatients, outpatients and observation patient types for the duration of the study from 2015 to 2019. For each year from 2015 to 2019, the total numbers of non-cardiac surgical encounters among patients with history of a CHD diagnosis were 38,272, 40,313, $41,454,43,854$, and 45,993, respectively $(\mathrm{P}<0.001)$. Demographics and patient characteristics of patients with CHD presenting for a non-cardiac procedure from 2015 to 2019 are presented in Table 1 . The age distribution, race and comorbidities remained similar over the 5-year study period. The distribution of patients in this cohort across the United States is displayed in Fig. 1.

Table 2 shows the number of encounters and mortality rates over time stratified by patient type. There was a significant increase in the number of inpatient encounters $(P=0.006)$ and outpatient encounters $(P<0.001)$ over time. The trend in number of observation unit encounters over time did not reach statistical significance $(\mathrm{P}=0.071)$. There was a significant downward trend in mortality rates in the entire cohort from 2015 to 2019; with mortality rates of $1.16 \%$ down to $1.06 \%(\mathrm{P}=0.01)$. The median length of stay was similar over the 5 years at 7 days in 2015, 2016, 2017 and 8 days in 2018 and 2019.

The number of encounters of patients without a diagnosis of CHD undergoing non-cardiac surgery increased over time $(447,503,457,044,461,735,467,146,489,535 ; \mathrm{P}=0.014)$, however the mortality rate in this group did not change significantly across these years $(0.13 \%, 0.13 \%, 0.11 \%, 0.12 \%$, and $0.12 \%$ respectively; $\mathrm{P}=0.226)$.

Table 3 shows the most common CHD diagnoses for each study year. These include: atrial septal defect, patent ductus arteriosus, ventricular septal defect, congenital insufficiency of aortic valve, stenosis of pulmonary artery, and hypoplastic left heart syndrome. Table 4 summarizes the most common non-cardiac outpatient procedures by year for patients with CHD. These include incision in the middle ear, myringotomy, esophagogastroduodenoscopy, and drainage of left middle ear with open approach. Table 5 summarizes the most common procedures for the encounters admitted for observation, which include: excision and destruction procedures on the pharynx, adenoidectomy, tonsillectomy, endoscopic procedures on the larynx, and bronchoscopy, rigid or flexible. The most common non-cardiac inpatient procedures by year among CHD patients are presented in Table 6 . These include: tracheostomy, abdominal wall repair, excision of ileum, restriction of esophagogastric junction, percutaneous endoscopic approach, insertion of feeding device percutaneously and ventricle to peritoneal shunt. 


\begin{tabular}{|c|c|}
\hline Outpatient procedures & Intrinsic surgical risk \\
\hline \multicolumn{2}{|l|}{2015} \\
\hline Excision and destruction procedures on the pharynx, adenoids, and tonsils & N/A \\
\hline Tonsillectomy and adenoidectomy & $\mathrm{N} / \mathrm{A}$ \\
\hline Endoscopy- procedures on the larynx & 1 \\
\hline Bronchoscopy, rigid or flexible & $2-3$ \\
\hline Myringotomy & 1 \\
\hline \multicolumn{2}{|l|}{2016} \\
\hline Excision and destruction procedures on the pharynx, adenoids, and tonsils & N/A \\
\hline Tonsillectomy & N/A \\
\hline Endoscopy-procedures on the larynx & 1 \\
\hline Bronchoscopy, rigid or flexible & $2-3$ \\
\hline Drainage of the middle ear & 1 \\
\hline \multicolumn{2}{|l|}{2017} \\
\hline Excision and destruction procedures on the pharynx, adenoids, and tonsils & N/A \\
\hline Tonsillectomy & $\mathrm{N} / \mathrm{A}$ \\
\hline Endoscopy-procedures on the larynx & 1 \\
\hline Bronchoscopy, rigid or flexible & $2-3$ \\
\hline Endoscopic procedure on trachea and bronchi & 1 \\
\hline \multicolumn{2}{|l|}{2018} \\
\hline Excision and destruction procedures on the pharynx, adenoids, and tonsils & N/A \\
\hline Tonsillectomy & N/A \\
\hline Endoscopy procedures on the larynx & 1 \\
\hline Bronchoscopy, rigid or flexible & $2-3$ \\
\hline Tympanostomy & 1 \\
\hline \multicolumn{2}{|l|}{2019} \\
\hline Excision and destruction procedures on the pharynx, adenoids, and tonsils & N/A \\
\hline Tonsillectomy & N/A \\
\hline Endoscopy procedures on the larynx & 1 \\
\hline Bronchoscopy, rigid or flexible & $2-3$ \\
\hline Laparoscopic procedures on the stomach & $1-2$ \\
\hline
\end{tabular}

Table 5. Most common procedures as observation ( $<24 \mathrm{~h}$ admission).

\section{Discussion}

The number of noncardiac procedures in patients with CHD at PHIS participating children's hospitals has increased steadily over the past 5 years. Despite the increase in case numbers, there has been a significant decline in mortality rates to the most recent incidence of $1.06 \%$ in 2019.

In a recent study using the ACS NSQIP pediatric database, children with CHD undergoing noncardiac surgery had a 30 -day mortality incidence of $1.7 \%$ in the derivation cohort and $1.5 \%$ in the validation cohort $(n=13,129)^{13}$. This mortality rate is higher than the rate reported in this study. This is most certainly due to differences in the underlying severity of CHD in the two cohorts. In the ACS NSQIP cohort $46.9 \%$ of patients had major or severe CHD and $67.9 \%$ of patients had unrepaired lesions; in the current cohort $>90 \%$ of patients would be classified as having minor CHD. Previous work by our group has demonstrated that in children with CHD, patient comorbidities, and severity of the cardiac lesion are the predominant predictors of 30-day mortality ${ }^{13}$. These differences in patient demographics as regards CHD severity are likely due to the fact that while the PHIS data includes inpatient, outpatient and observation unit encounters at dedicated children's hospitals, the ACS NSQIP data includes only inpatient pediatric cases and the participating hospitals include freestanding hospitals, children's hospitals within larger hospitals, specialty children's hospitals or general acute care hospitals with a pediatric wing ${ }^{10-14}$.

While the mortality rate in CHD patients improved, the mortality rate in patients without CHD remained relatively constant at $0.12 \%$ over the 5 -year study period. The mortality rate in this cohort is comparable to that seen in other studies. Among the 183,423 children included in the 2012 to 2014 ACS NSQIP database, the incidence of mortality was $0.5 \%(563 / 115,229)$ in the derivation cohort and $0.4 \%(290 / 67,904)$ in the validation cohort ${ }^{15}$. Among the 13,530 cases included in a subsequent external validation cohort, the incidence of 30-day mortality was $0.21 \%(29 / 13,530)^{16}$. In a more recent study using the ACS NSQIP database, the overall 30-day mortality in 367,065 surgical cases encompassing 659 unique Current Procedural Terminology codes was $0.34 \%{ }^{13}$. Obviously, these studies speak to the high quality of perioperative care currently rendered to children undergoing surgery.

The most common types of noncardiac procedures performed on CHD patients remained constant over the 5 -year study period. Gastrointestinal and otolaryngologic procedures were the most common. This is consistent 


\begin{tabular}{|c|c|}
\hline Inpatient procedures & Intrinsic surgical risk \\
\hline \multicolumn{2}{|l|}{2015} \\
\hline Gingivoplasty & N/A \\
\hline Peritoneal adhesiolysis & 1,3 \\
\hline Partial resection of the small intestine & 3 \\
\hline Restriction of esophagogastric junction, percutaneous endoscopic approach & 1 \\
\hline Cerebral ventricle to peritoneal cavity & 4 \\
\hline \multicolumn{2}{|l|}{2016} \\
\hline Abdominal wall repair & $1-4$ \\
\hline Tracheostomy & 4 \\
\hline Insertion of feeding device into stomach, percutaneous approach & 3 \\
\hline Restriction of esophagogastric junction, percutaneous endoscopic approach & 1 \\
\hline Excision of ileum & $3-4$ \\
\hline \multicolumn{2}{|l|}{2017} \\
\hline Abdominal wall repair & $1-4$ \\
\hline Tracheostomy & 4 \\
\hline Insertion of feeding device into stomach, percutaneous approach & 3 \\
\hline Excision of ileum & $3-4$ \\
\hline Cerebral ventricle to peritoneal cavity & 4 \\
\hline \multicolumn{2}{|l|}{2018} \\
\hline Tracheostomy & 4 \\
\hline Abdominal wall repair & $1-4$ \\
\hline Insertion of feeding device into stomach, percutaneous approach & 3 \\
\hline Excision of ileum & $3-4$ \\
\hline Cerebral ventricle to peritoneal cavity, open approach & 4 \\
\hline \multicolumn{2}{|l|}{2019} \\
\hline Tracheostomy & 4 \\
\hline Abdominal wall repair & $1-4$ \\
\hline Excision of ileum & $3-4$ \\
\hline Insertion of feeding device into stomach, percutaneous approach & 3 \\
\hline Drainage of cerebral ventricle with device, percutaneous approach & $3-4$ \\
\hline
\end{tabular}

Table 6. Most common inpatient noncardiac procedures.

with a previous study which demonstrated that general surgical and otolaryngologic procedures to be the most common procedures performed in the first 5 years of life in children requiring infant cardiac surgery ${ }^{4}$. Assignment of our intrinsic surgical risk (ISR) classification to the procedures performed on patients in this cohort demonstrated that most of the noncardiac procedures performed in the outpatient and observation settings are low risk with an ISR of $1^{13}$. A limitation of the ISR is that tonsillectomies are not included in the classification as this procedure is not reported to the ACS-NSQIP database from which the ISR was derived. The ISR for procedures performed on the inpatient cohort ranged from 1 to 4 . Clearly, the more complex surgical procedures are performed in the inpatient setting as would be expected.

Careful patient selection and medical optimization of patients aligned with specific expertise at dedicated children's hospitals may lead to additional improvement in mortality rate over time in patients with CHD undergoing non-cardiac surgery. It has been demonstrated that collaboration and transparency between institutions leads to reductions in-hospital mortality, duration of mechanical ventilation, length of stay and major complications following pediatric cardiac surgery. In children's hospitals participating in the Pediatric Cardiac Critical Care Consortium (PC4) outcomes improved over a 2-year period while non-participating hospitals showed no improvement in outcomes over this time interval ${ }^{17}$. It has been suggested that regionalization of care at specialized hospitals can reduce mortality for congenital heart surgery as well ${ }^{18}$. Children with CHD, especially those with unrepaired lesions or with a residual lesion burden and compromised cardiovascular status require an individualized approach to anesthetic and surgical care delivered by trained multidisciplinary teams ${ }^{19,20}$. Practitioners including cardiologists, intensivists, and primary care physicians who care for children with CHD must address a number of challenges including identifying the best location for procedures (e.g., children's hospital), identifying qualified team (e.g., cardiac anesthesiologists, surgeons), and utilizing the expertise of the non-cardiac subspecialties (e.g., nephrology, hematology, pediatricians).

This study has several limitations. The PHIS database is an administrative database and miscoding of CHD may occur ${ }^{21-23}$. Since the results are based on only the 39 children's hospitals that participated during the past 5 years by contributing all types of patients encounters, the generalizability of the results is limited. While using ICD 9 and 10 in the PHIS database provides the information about the cardiac diagnosis and surgical procedure, it lacks the granularity in regard to the severity of the cardiac disease which is necessary to further categorize the 
cardiac disease based on functional severity and degree of residual cardiac lesions. In addition, we looked at the trends over 5 years, which led to the inclusion of ICD 9 in the 2015 data. The ICD 9 coding were converted to ICD 10 in 2015. We used the conversion of ICD 9 to ICD 10 to sum the number of procedures and cardiac diagnosis.

In conclusion, this analysis of the PHIS database points out that the mortality rate of patients with CHD undergoing noncardiac procedures is improving despite the increase in number of noncardiac procedures performed per year. Future studies comparing the outcomes of patients with cardiac disease based on hospital type and volume as well as the provider experience (pediatric cardiac versus general pediatric anesthesiologist) may help determine the future of care including potential need for regionalization of noncardiac care for this vulnerable patient population.

Received: 23 October 2020; Accepted: 1 January 2021

Published online: 15 January 2021

\section{References}

1. Hoffman, J. I. E. \& Kaplan, S. The incidence of congenital heart disease. J. Am. Coll. Cardiol. 39, 1890-1900 (2002).

2. Gilboa, S. et al. Mortality resulting from congenital heart disease among children and adults in the United States, 1999 to 2006. Circulation 122, 2254-2263 (2012).

3. Marelli, A. J. et al. Lifetime prevalence of congenital heart disease in the general population from 2000 to 2010 . Circulation 130, 749-756 (2014).

4. Sulkowski, J. P. et al. Variability in noncardiac surgical procedures in children with congenital heart disease. J. Pediatr. Surg. 49, 1564-1569 (2014)

5. Baum, V. C., Barton, D. M. \& Gutgesell, H. P. Influence of congenital heart disease on mortality after noncardiac surgery in hospitalized children. Pediatrics 105, 332-335 (2000)

6. Ramamoorthy, C. et al. Anesthesia related cardiac arrest in children with heart disease: Data from the Pediatric Perioperative Cardiac Arrest (POCA) registry. Anesth. Analg. 110, 1376-1382 (2010).

7. Flick, R. P. et al. Perioperative cardiac arrests in children between 1988 and 2005 at a tertiary referral center: A study of 92,881 patients. Anesthesiology 106, 226-237 (2007).

8. van der Griend, B. F. et al. Postoperative mortality in children after 101,885 anesthetics at a tertiary pediatric hospital. Anesth. Analg. 112, 1440-1447 (2011).

9. Faraoni, D. et al. Post-operative outcomes in children with and without congenital heart disease undergoing noncardiac surgery. J. Am. Coll. Cardiol. 67, 793-801 (2016).

10. https://www.childrenshospitals.org/phisICDcodes. Accessed Oct 2020.

11. https://www.cdc.gov/nchs/icd/index.htm. Accessed Oct 2020.

12. Nasr, V. G., Staffa, S., Zurakowski, D., DiNardo, J. \& Faraoni, D. Pediatric risk stratification is improved by integrating both patient comorbidities and intrinsic surgical risk. Anesthesiology 130(6), 971-980 (2019).

13. Faraoni, D., Zou, X., DiNardo, J. A. \& Nasr, V. G. Integration of the intrinsic surgical risk with patient comorbidities and severity of congenital heart disease does not improve risk stratification in children undergoing non-cardiac surgery. Anesth. Analg. 131(4), 1083-1089 (2020).

14. https://www.facs.org/quality-programs/childrens-surgery/pediatric/overview. Accessed July 2020.

15. Nasr, V. G., DiNardo, J. A. \& Faraoni, D. Development of a pediatric risk assessment (PRAm) score to predict perioperative mortality in children undergoing non-cardiac surgery. Anesth. Analg. 124(5), 1514-1519 (2017).

16. Valencia, E., Staffa, S., Faraoni, D., DiNardo, J. A. \& Nasr, V. G. Prospective external validation of the PRAm score in predicting perioperative mortality in children undergoing noncardiac surgery. Anesth. Analg. 129(4), 1014-1020 (2019).

17. Gaies, M. et al. Improvement in pediatric cardiac surgical outcomes through interhospital collaboration. J. Am. Coll. Cardiol. 74(22), 2786-2795 (2019).

18. Welke, K. F. et al. Regionalization of congenital heart surgery in the United States. Semin. Thorac. Cardiovasc. Surg. 32(1), 128-137 (2020).

19. Brown, M. L., DiNardo, J. A. \& Nasr, V. G. Anesthesia in pediatric patients with congenital heart disease undergoing non-cardiac surgery: Defining the risk. J. Cardiothorac. Vasc. Anesth. 34(2), 470-478 (2020).

20. Taylor, D. \& Habre, W. Risk associated with anesthesia for noncardiac surgery in children with congenital heart disease. Paediatr. Anaesth. 29(5), 426-434 (2019).

21. Cronk, C. E. et al. Completeness of state administrative databases for surveillance of congenital heart disease. Birth Defects Res. A Clin. Mol. Teratol. 67(9), 597-603 (2003).

22. Frohnert, B. K. et al. Validity of hospital discharge data for identifying infants with cardiac defects. J. Perinatol. 25(11), 737-742 (2005).

23. Strickland, M. J. et al. The importance of nomenclature for congenital cardiac disease: Implications for research and evaluation. Cardiol. Young. 18 Suppl 2(0 2)(2), 92-100 (2008).

\section{Author contributions}

V.G.N.: this author designed the study, extracted the data, interpreted the statistical analysis, wrote the manuscript, approved the final version. S.J.S.: this author helped with the study design, performed and interpreted the statistical analyses, helped write the manuscript and approved the final version. J.A.D.: this author helped design the study, helped write the manuscript and approved the final version. D.F.: this author helped design the study, helped write the manuscript and approved the final version.

\section{Funding}

This study was solely supported by the Department of Anesthesiology, Critical Care and Pain Medicine at Boston Children's Hospital, Harvard Medical School, Boston, Massachusetts.

\section{Competing interests}

The authors declare no competing interests.

\section{Additional information}

Correspondence and requests for materials should be addressed to V.G.N. 
Reprints and permissions information is available at www.nature.com/reprints.

Publisher's note Springer Nature remains neutral with regard to jurisdictional claims in published maps and institutional affiliations.

(c) (i) Open Access This article is licensed under a Creative Commons Attribution 4.0 International License, which permits use, sharing, adaptation, distribution and reproduction in any medium or format, as long as you give appropriate credit to the original author(s) and the source, provide a link to the Creative Commons licence, and indicate if changes were made. The images or other third party material in this article are included in the article's Creative Commons licence, unless indicated otherwise in a credit line to the material. If material is not included in the article's Creative Commons licence and your intended use is not permitted by statutory regulation or exceeds the permitted use, you will need to obtain permission directly from the copyright holder. To view a copy of this licence, visit http://creativecommons.org/licenses/by/4.0/.

(C) The Author(s) 2021 